\title{
Genetiese merkers in die bloed van diere - 'n geskiedkundige oorsig
}

\author{
D.R. Osterholf \\ Departement Etologic, Fakulteit Vecartsenykunde, Universiteit van Pretoria, Pretoria, 0002
}

Onvang 15 Oktober 1996; anvan 4 April 1997

\section{UITTREKSEL}

In hievdie oorsig is gepoog om die belangrikste gebeurtenisse in die soeke na genetiese merkers in die bloed van diere aan te haal. In volgorde is bloedgroepe, biochemiese polimorfismes, limfosiet-antigene en DNS-merkers ontek en in die praktyk gebruik.

Van al die praktiese toepassings het onerskap- en vaderskapbepalings die meeste belangstelling verky en dit kan met trots genoem word dat ook die Suid-Afrikanse Stamboek se gegewens as korrek beskou kan word.

\section{A ibstract}

\section{Genetic markers in the blood of animals - a historical overview}

In this review an attempt is made to list the most important events in the search for genetic markers in the blood of amimals. In chronological order there are blood groups, biochemical polymorphisms, lymphocyle antigens and the DNA markers that have been discovered and used in practice.

Of all practical ases the parenage verification and exclusion are regarded as most important and it can be said with pride that the South African Stud Book is as infallible as any other studbook in the wortd.

\section{INLEIDING}

Die studie van genetiese merkers in die bloed van diere het reeds honderd jaar gelede 'n aanvang geneem toe Landsteiner in 1900 individuele verskille in die bloed van bokke waargeneem het.' Sonder om in te veel tegniese besonderhede in te gaan, sal in hicrdic oorsig aangetoon word wat veral in die laaste dekades ten opsigte van genetiese merkers bereik is.

Van al dic praktiese tocpassings - ingesluit die diagnose van tweelinge, vrocë diagnose van kwene, studies van populasiestruklure, verandering van graad van inteling, studies van geslagsgedrag in kuddes en verwante probleme het ouerskap-en vaderskapbepalings die meeste belangstelling van boere en telersverenigings gekry. Die toepaslike waarde van hicrdie toetse is gou besef en telersgenootskappe mak ten volle gebruik daarvan. Op die wyse word hulle lede verseker dat dic Suid-Alrikaanse Stambock so onfeilbaar as moontlik is.

Die basiese beginsel van ouerskapbepaling berus op die Mendelse wette: Die Mendelse wet van dominansic sluit 'n nageslag uit as die 'n merker besit wat nie ten minste by een van dic ouers voorkom nie. Dic Mendelse wet van segregasic sluit 'n ouer uit wat nie deel het in 'n genetiese merker wat aan 'n nageslag oorgedra moes gewees het nic.

Die studie van genetiese merkers, veral dic van rooibloedselantigene, het na die Tweede Wêreldoorlog met rasse skrede vooruitgegaan. Stormont het 'n fenomenale bydrae gelewer deurdat hy dic blocdgrocpe van beeste recds in die vyftigerjare in genetiese sisteme geplaas en veral die B-sisteem met meer as 600 allele gerangskik het. ${ }^{2}$

Dic ontplooiing ook in ander diersoorte was besonder snel en in 1996 was daar nic minder nic as 102 laboratoriums wêreldwyd waar navorsers besig is om geneticse merkers op te spoor en in die verbetering van plaasdiere te benut. Veral in die VSA waar nuwe tegnicke ontwikkel is, hel die ontdekking van groot reekse immunogenetiese verskille met rasse skrede vooruitgegaan en daar is tans elf laboratoriums, waarvan die meeste as leiers op die gebied beskou kan word.

\section{DIE STAND VAN BIOEDGROEPE AS GENETIESE MERKERS BY DIERE}

Bloedfaktore op die rooiblocdselle (rooisel-antigene) wat deur agglutinasic of hemolise bepaal word, was die ecrste van die genetiese merkers wat volledig nagevors is. Dit is van pas om die stand van sake by beeste, skape, varke, perde en honde in die volgende tabel te toon. ${ }^{3}$

\begin{tabular}{|c|c|c|c|}
\hline Diersoort ${ }^{*}$ & $\begin{array}{c}\text { Getal } \\
\text { Sisteme }\end{array}$ & $\begin{array}{c}\text { Getal } \\
\text { Bloedfaktore }\end{array}$ & $\begin{array}{l}\text { Getal } \\
\text { Allele }\end{array}$ \\
\hline Beeste & 11 & 121 & 709 \\
\hline Skape & 7 & 22 & 69 \\
\hline Varke & 15 & 76 & 76 \\
\hline Perde & 7 & 26 & 36 \\
\hline Honde & 11 & 12 & 24 \\
\hline
\end{tabular}

" Die oorerwing van bloedgroepe by bokke en $^{4}$ atte ${ }^{3}$ is nog nie volledig opgeklaar nie, dus is dié twee diersoorte nie in die tabel ingesluit nie.

Die sock na nuwe rooibloedsel-antigene en -allele het sy hooglepunt in die sestigerjare gehad. In die tagtigerjare het hierdie navorsing prakties tot 'n einde gekom en 'n klemverskuiwing na ander genetiese merkers het plaasgevind.

\section{BIOCHEMIESE POIIMORFISMES}

Dic bepaling van biochemiese polimorfismes deur elektroforese het tot die ontdekking van 'n grool verskeidenheid genetiese merkers gelei. Verskillende media soos stysel. agarose of akriclamied-jel word in dic elektroforese gebruik om geneticse verskille tussen diere in die proteiene en ensieme sigbaar te maak. By alle diersoorte is daar' $n$ groot aantal sisteme met die toepaslike allele gevind. As voorbeeld word in tabel 2 die huidige 
stand van die ondersoek na biochemiese polimorfismes by perde getoon, soos dit huidig in dic laboratoriums te Onderstepoort uitgevoer word. ${ }^{5.6}$

\begin{tabular}{|c|c|c|}
\hline Sisteem & $\begin{array}{l}\text { Lokus- } \\
\text { simbool }\end{array}$ & $\begin{array}{l}\text { Erkende } \\
\text { allele }\end{array}$ \\
\hline $\begin{array}{l}\text { Albumien } \\
\text { Suurfosfatase } \\
\text { Karboonanhidrase } \\
\text { Katalase } \\
\text { NADH-diaforase } \\
\text { Esterase } \\
\text { Peptidase } \\
\text { Vit. A-bindingsproteïen } \\
\text { Hemoglobien } \\
\text { 6-fosfoglukonaat- } \\
\text { dehidrogenase } \\
\text { Fosfoglukomutase } \\
\text { Fosfoheksose- } \\
\text { isomerase } \\
\text { Protease-inhibeerder } \\
\text { Transferrien } \\
\text { A1B Glukoproteien } \\
\text { Glukofosfo-isomerase } \\
\text { Plasminogeen }\end{array}$ & $\begin{array}{l}\text { ALB } \\
\text { AP } \\
\text { CA } \\
\text { Cat } \\
\text { Dia } \\
\text { Es } \\
\text { Pep A } \\
\text { Gc } \\
\text { Hb } \\
\text { PGD } \\
\text { P G M } \\
\text { PHI } \\
\text { Pi } \\
\text { Tf } \\
\text { A1B } \\
\text { GPI } \\
\text { PLG }\end{array}$ & $\begin{array}{l}A B 1 \\
F S \\
E F I L O S \\
F S \\
F S \\
F G H I L M O R S \\
F S \\
F S \\
A A l l B I B I N V \\
D F S \\
F S V \\
F I S \\
F G H I J K L_{1} L_{2} N O \\
P Q R S T U V W Z \\
D D_{2} E F_{1} F_{2} \\
F_{3} G H_{1} H_{2} J M O R \\
F K S \\
F I L S \\
12\end{array}$ \\
\hline
\end{tabular}

Internasionaal word toetse van bloedgroepe en biochemiese merkers nog as standaarde vir oucrskapkontrole aanvalar, maar daar word reeds DNS-toetspanele wêreldwyd beskikbaar gestel.

\section{DIE HOOFWEEFSEIVERENIGIBAARHEIDSKOM- PLEKS (HWK)}

Dit is bekend dat oorgeplante organe en weefsels in die meeste gevalle deur die ontvanger verwerp word. As die skenker egter aan dic ontvanger verwant is, word die verwerpingsreaksic beduidend verminder, wat dus op die genetiese basis vir dic reaksie dui.

Die naturlik voorkomende seloppervlakle-antigene (limfosiet-antigene LA) wat hicrvoor verantwoordelik is, word hoofweelselverenigbaarheidskompleks (HWK) genoem (Eng. major histocompatibility complex MHC). 'n Goeie uiteensetting van die HWK-sisteme word deur Newman en Antezek ${ }^{7}$ gegee.

Tabel 3 verduidelik die belangrikste HWK-sisteme. ${ }^{*}$

TABEL 3 Die nomenklatuur van die HWK by verskillende spesies $^{8}$

\begin{tabular}{|l|l|l|}
\hline Spesie & Naam & Simbool \\
\hline \hline Muis & H-2 & H-2 \\
Rot & RT1 & RT1 \\
Hond & hondlimfosiet-antigeen & DLA \\
Vark & varklimfosiet-antigeen & SLA \\
Bok & boklimfosiet-antigeen & GLA \\
Skaap & skaaplimfosiet-antigeen & OLA \\
Bees & beeslimfosiet-antigeen & BoLA \\
Perd & perdlimfosiet-antigeen & ELA \\
Resusaap & resuslimfosiet-antigeen & RhLA \\
Mens & menslimfosiet-antigeen & HLA \\
\hline
\end{tabular}

By muise is die meeste navorsingswerk voltooi en meer as 30 genetiese lokusse is geïdentifiseer. ${ }^{8}$ In die jare tagtig het studies op limfosiet-antigene (LA) met groot skrede vooruit gegaan. Iloolsalaklik by beeste (BoLA), maar ook by varke (SLA) en perde (ELA) word die moontlike verband tussen HWK en sicktetoleransic nagevors.

\section{DNS-MERKERS}

Dic ondersocke van deoksiribonukleiensuur (Eng. DNA) het die deurbraak in die negentigerjare behaal, en sal mettertyd die bogenoemde geneliese merkers, die rooiselanligene, dic biochemiese polimorfismes en die hoofweefselverenigbarrheidskompleks vervang.

Die groot voordecl van die DNS-bepalings is die direkte ondersocke van genetiese materiaal en enige bron van DNS. byvoorbecld bloed en halarwortels is geskik. Die feil dall die DNS-toetsing nic aan vars blocdmonsters gebind is nie, het 'n socke in ticntalle laboratoriums alan dic gang gesil.

Daar word vergelykings getrel tussen veclvoudige lokusvingerafdrukke (=minisatellicte), restriksiefragment-lengtepolimorlisme (RFLP - Eng. RFLP = restriction lragment length polymorphism), dialleliese sisteme of enkelnukleotiedpolimorfisme (ENP - Eng. SNP = single nucleotid polymorphism) en mikrosateliete, ook bekend as kort tandemherhalings (K'TH - Eng. STR = short tandem repeats). ${ }^{5}$

In hierdie stadium blyk dit dat die mikrosatcllict-legnick dic gewildste is in die soeke na geneliese verskille. Die genetiese variasie in mikrosatelliete word bepaal deur van die polimerasekettingreaksie (PKR - Eng. PCR = polymerase chain reaction) saam met elektrolorese gebruik te malak. Die DNS-beginslukke (Eng. primer), wall dic mikrosatellictstreck omsluit, dui dic rigting van die samestelling van 'n spesilicke chromosoomgedecte aan. Beginnende met'n klein hoeveclheid - soveel as 'n enkele geenkopic - kan dic polimerase-kettingreaksic dic DNS-volgorde gedurende 'n paar ure miljoenvoudig dupliseer. Die tandemberhalings word deur die analise van die rragmentgrootte na die elektroforese van die PKR-produkte sigbalar gemaak. ${ }^{5}$

Gedurende die XXV Internasionale Konferensic oor Dieregenetika in Tours, Frankryk is besluit om die nomenklatuur van die DNS-mikrosatelliete internasional te standaardiseer. Die letters A tol $Z$ sal gebruik word van die kleiner na die groler allele, me die letter $M$ as die natam vir die middelalleel."

Tabel 4100 n dic ontwikkeling aan van die navorsing oor genetiese merkers in die bloed van diere gedurende die labste dertig jaar. ${ }^{10}$

TABEL 4 Bydraes van navorsers gedurende verskillende konferensies (in persentasie) ${ }^{10}$

\begin{tabular}{|l|c|c|c|c|}
\hline Onderwerpe & 1964 & 1974 & 1984 & 1994 \\
\hline \hline Bloedgroepe & 58 & 42 & 18 & 5 \\
\hline Biochemiese polimorfismes & 34 & 50 & 48 & 18 \\
\hline $\begin{array}{l}\text { Hoofweefselverenigbaar- } \\
\text { heidskompleks }\end{array}$ & 8 & 8 & 33 & 17 \\
\hline DNS en Geenkartering & 0 & 0 & 1 & 60 \\
\hline
\end{tabular}

Groot verskuiwings van sludies op bloedgroepe en biochemiese polimorlismes na molekulêre genetiese studies (DNS) oor die lydperk van 30 jaar is baic duidelik. Hierdie lendens kan gesien word in die bydraes gedurende die 1996-konferensic 1e Tours (label 5)." 


\begin{tabular}{|l|c|c|}
\hline \multicolumn{3}{|c|}{$\begin{array}{l}\text { TABEL } 5 \text { Bydraes van navorsers gedurende die } \\
\text { 1996-konferensie te Tours, Frankryk }\end{array}$} \\
\hline Onderwerpe & $\begin{array}{c}\text { Getal } \\
\text { bydraes }\end{array}$ & $\begin{array}{c}\text { Persen- } \\
\text { tasie }\end{array}$ \\
\hline \hline Polimorfismes en biodiversiteit & 105 & 26 \\
\hline $\begin{array}{l}\text { Hoofweefselverenigbaarheids- } \\
\text { kompleks }\end{array}$ & 47 & 12 \\
\hline Geenkartering & 118 & 30 \\
\hline Molekulêre genetika & 51 & 13 \\
\hline $\begin{array}{l}\text { Assosiasie tussen merkers en } \\
\text { eienskappe }\end{array}$ & 76 & 19 \\
\hline
\end{tabular}

Weereens het 'n verskuiwing plaasgevind, van die ondersocke van polimorfismes waarby blocdgroepe en DNS-merkers ingesluit is na geenkantering en assosiasies tussen genetiese merkers en kwalitatiewe en kwantitatiewe eienskappe by diere.

\section{DIE TOEPASSINGSWAARDE VAN GENETIESE MERKERS}

Die toepaslike waarde van genetiese merkers is ook in SuidAfrika besel en reeds vanaf 1957 is vaderskapbepalings by beeste uitgevoer.

In die sestigerjare is in Suid-Afrika uitsluitlik bloedfaktore gebruik en $92,5 \%$ van alle ouerskapsgevalle kon opgelos word. " (Daar is ooreenstemmende faktore by ouers en nageslag wat oplossing onmoontlik maak.) In latere jare is meer en meer proteien- en ensiemmerkers gebruik en die persentasie oplossings kon na $98 \%$ opgestoot word. Daar word nou in SuidAfrika gewerk om DNS-merkers in te sluit om sodoende op 'n persentasie van nagenoeg $100 \%$ te kom.

Embrio-oorplasing by beeste het die belangrikheid van ouerskapbewyse noodsaaklik gemaak en die toepassingswaarde van genetiese merkers by beeste verhoog. Die aantal fouticwe ouerskappe staan tans op drie persent. ${ }^{12}$

By skape het die belangrikheid van genetiese merkers by in vitro-bevrugting en klonering duidelik geword. Ook populasiestudies is van belang, soos uit die enkele voorbecld van 'n karakoelvergelyking blyk..$^{13}$

By varke is prestasie- en nageslagskemas besonder belangrik, maar groot kostes is daaraan verbonde. Die identilikasie van varke wat aan hierdie skemas declneem, is vir dié redes onontbeerlik.

By perde is die perdepaspoort, wat alle genetiese merkers insluit, nou van groter belang aangesien Suid-Afrikaanse resiesperde weer vanaf 1997 op internasionale renbane kan meeding. Gedurende die jaar 1996/97 kon 99,5 persent van alle ouerskapgevalle opgelos word. Soos by becste was dic aantal fouticwe ouerskappe by perde drie persent. ${ }^{\circ}$

By honde brei die identifikasie van rasse en die kontrole van ouerskappe steeds uit, aangesien die beweging van honde oor landsgrense heen al hoe belangriker word."

\section{GENETIESE MERKERS IN HUIDIGE EN TOEKOM- STIGE NAVORSING}

Soos in tabel 5 aangedui, is die geenkartering reeds voluit aan die gang. Gedurende dic Tours-konferensie was daar nie minder nie as 118 bydraes oor geenkartering by alle belangrikste plaasdierspesies. ${ }^{9}$ Hierdie navorsing is nie van direkte voordeel vir dieretelers nie, maar sal van nut wees in die toepassing van korrelasies tussen gene en siektetoleransie van diere. Die inligting sal lei tot beter begrip van genetiese tendense soos die BLUP-analise (Eng. BLUP = best linear unbiased prediction).

'n Nuwe rigting in die gebruik van genetiese merkers is MOS $=$ merkcrondersteunende seleksie $($ Eng. MAS $=$ marker assisted selection).

Aangesien die getal merkers by die verskillende spesies meer $\mathrm{en}$ meer bekend geraak het, was dit voor die hand liggend om die loci van merkers en daarmee saam die kwantitatiewc eienskap-loci (KEL - Eng. QTL = quantitative trait loci) op to spoor. Die veelvoudige navorsing wêreldwyd is weerspieêl in 76 bydraes wat die assosiasic tussen merkers en hoofsaaklik kwantitatiewe eienskappe probeer ontrafel (sien tabel 5).

Die volledige geenkartering is die hocksteen vir die soeke na die kwantitaticwe eienskap-loci (KEL) wat dan in die merkers ondersleunende seleksie (MOS) van diere sy deurslag vind. Van die molekulêr-genetiese metodes en die gebruik daarvan in die verwesenliking van teeldoelwitte word groot deurbrake verwag. ${ }^{14}$

Hoe meer merkers gevind word, hoe meer kompleks is die soeke na korrelasies en assosiasies tussen merkers en kwalitatiewe en kwantitatiewe eienskappe. Wat dic oorerflike sicktes betref, kon die volgende deur molekulêr-genetiese metodes gediagnoseer word: Kardiomiopatic (Eng. CMP), spinale muskulêre atrofie (Eng. SMA), uridienınonofosfaat-sintesetekort (Eng. DUMPS), bees progressicwe degeneratiewe miëloënsefalopatic (Eng. BPDME), bees spongiforme enkefalopatic (Malkoeisiekte) (Eng. BSE) en bees-limfosict-antigeen-tekorte (Eng. BLAD). ${ }^{1+}$

Molckulêr-genctiese tegnicke is ook van toepassing by infeksiesicktes soos beesleukose, becsrinotracheïtis, bruscllose, bek- en klouseer en ander.

Maar dic groot uitdaging lê op die gebied van MOS - merker ondersteunende seleksie. As daar merkers gevind word wat gekoppel kan word aan siekte of wat 'n direkte verband met vrugbaarheids-, groci- of produksie-eienskappe toon, was alles die moeite werd.

\section{SUMMARY}

An attempt is made to give an overview of the development in the field of research on genetical markers. During the last fifty years the progress made was phenomenal and it is impossible to do justice to all the contributors throughout the world.

Blood group antigens, biochemical polymorphisms, lymphocyte antigens and DNA markers have been discussed in chronological order.

The practical uses of genetical markers are extensive, but parentage verification is the most important. With regard to the South African Stud Book it can be said with pride that only three percent of registrations were inaccurate. The field of research in the uses of genetical markers is wide open, considering the search for associations between markers and diseases or markers and qualitative and quantitative traits. The new direction of research is MAS = marker assisted selection. Several results have been accomplished but the road ahead is certainly not an casy one.

\section{LITERATUURVERWYSINGS}

I. Landsteiner, K. (1901). Über Agglutinationserscheinungen normalen menschlichen Blutes, Wien. Klin. Wsc/hr. 14, 1132-1134.

2. Stormont, C. (1962). Current status of blood groups in cattle, Ann. N.Y. Acad. Sci., 97, 251-268.

3. Agar, N.S., Board, P.E. (ed.) (1983). Red blood cells of donestica mammals (Elsevier, Amsterdam, New York, Oxford) 
4. Osterholf, D.R. (1995). Studies on blood groups and biochemical polymorphisms in goats, Arch. Tierz., 38, 553-561.

5. Bowling, A.I. (1996). Horse Geneties (CAB International, Wallingford).

6. Van Dyk, E. (1997). Hoof: Bloedgroeplaboratorium (Perde) Fak. Veeartsenykunde, Onderstepoort. Persoonlike mededeling.

7. Newman, M.J., Antczak, D.R. (1983). Histocompatibility polymorphisms of domestic animals, Adr. Vel. Sci. Comp. Med., 27, 1-76.

8. Nicholas, F.W. (1987), Veterinary genelics (Claredon Press, Oxfor(l).

9. Handelinge. (1996). XXV Internasionale Konferensic oor Dieregenelika, Tours, Frankryk.
10. Handelinge. (1994). XXIV Internasionale Konferensic oor Dieregenerika, Praag. Tsjeggiese Republick.

11. Osterhoff, D.R. (1968). A decade of applied bovine blood grouping in the Republic of South Alrica, Proc: S. Afr: Soc: Anim. Prod. 1968, 163-169.

12. Du Plessis, S.J. (1996). Hool: Bloedgrocplaboratorium (Beeste) Landbounavorsingsraal, Diereverbeteringsinstituut. Irene. Persoonlike mededeling.

13. Nguyen, T.C., OsterhofT, I.R. (1992). Comparison between Russian and South African Karakul sheep based on blood group markers, Jl. S. Afr: vet. Ass., 63, 20-22.

14. Stranzinger, G.F. (1994). Realisicrbarkeit von Zuchtziclen mis Hilfe von molekulargenetischen Methoden, Zïchnmeskimde, 66, 484-488. 